\title{
Socio-economic determinants for malaria transmission risk in an endemic primary health centre in Assam, India
}

\author{
Kavita Yadav ${ }^{1}$, Sunil Dhiman ${ }^{*}$, Bipul Rabha ${ }^{1}$, PK Saikia ${ }^{2}$ and Vijay Veer ${ }^{1}$
}

\begin{abstract}
Background: Malaria is a major cause of morbidity and mortality in Northeast India. As there is limited information available on the potential influence of socio-economic variables on malaria risk, the present study was conducted to assess the influence of demographic factors, the socio-economic status, and knowledge, awareness and education on malaria occurrence.
\end{abstract}

Methods: Demographics, malaria knowledge and socio-economic variables were collected in four randomly selected health sub-centres of the Orang primary health centre in the Udalguri district, Assam and the association of malaria occurrence with different variables were analysed. The trend of malaria occurrence for different income groups, proximity to health centres and number of mosquito bites per day was also determined using the chi-square test. Relative risk (RR) for gender, house type, knowledge and use of bed nets was determined using Katz approximation.

Results: Out of the 71 household heads interviewed, 70.4\% (50/71) were males. About half (54.9\%, 39/71) of the participants had a history of malaria in the last two years, of which $64.1 \%(25 / 39)$ were males, while $35.9 \%(14 / 39)$ were females $\left(x^{2}=5.13 ; p=0.02 ; R R=1.79\right)$. Of the total population surveyed, $49.3 \%$ lived in bamboo houses and $35.2 \%$ lived at a distance of $>3 \mathrm{~km}$ from the nearest health centre. The number of participants who had a history of malaria decreased with an increasing monthly income $(p<0.0001)$. Malaria occurrence was higher among the households living in bamboo houses (69.2\%), as compared to Kucha houses (20.5\%) and Pucca houses (10.3\%). No significant association was observed between education level and malaria occurrence $(p=0.93)$. The participants who did not use bed nets regularly reported a high occurrence of malaria infection as compared to those who used bed nets everyday $(p<0.0001)$.

Conclusions: Lower income, house type, distance to health sub-centre, knowledge and awareness about malaria, number of mosquito bites per day and use of bed nets were positively associated with malaria occurrence. Increasing the number of health sub-centres close to rural areas, improving the economic status and increasing awareness about malaria prevention measures will thus help to reduce malaria-associated morbidities.

Keywords: Malaria risk factors, Socio-economic, Awareness, Udalguri, Assam

\section{Multilingual abstracts}

Please see Additional file 1 for translations of the abstract into the six official working languages of the United Nations.

\section{Background}

According to the World Health Organization's (WHO's) latest estimates, about 207 million malaria cases (range:
135-287) and approximately 0.63 million deaths (range: 0.47-0.79) were reported in 2012 [1]. Malaria has a higher inequality in distribution than any other disease of public health importance, as about $58 \%$ of malaria deaths occur among the poorest $20 \%$ of the world's population [2]. Endemic malaria results in tremendous economic losses annually and is a central element of the vicious cycle of poverty in many developing countries $[3,4]$. The global malaria control strategy

\footnotetext{
* Correspondence: sunildhiman81@gmail.com

1Defence Research Laboratory, Tezpur, Assam 784001, India

Full list of author information is available at the end of the article
} 
has largely emphasised malaria control by insecticidetreated bed nets (ITNs), including long-lasting insecticidal nets (LLINs), indoor residual spraying (IRS), increased case detection and subsequent treatment, as well as other vector control interventions, but comparatively less emphasis has been given to the socio-economic depression complex from which people have difficulty singling out malaria for various concerns $[1,5]$. The people living in malaria endemic countries with many other scourges, such as hunger, poverty and other diseases cannot understand why they would target malaria rather than make efforts to eliminate poverty and hunger. Therefore, in addition to strengthening the healthcare system, the success of malaria control depends significantly upon the knowledge and socio-economic status of the affected populations in the malaria endemic countries. Malaria is frequently referred to as a disease of the poor and the economic status of populations at risk has proved to be a great challenge in malaria control programmes [6]. Malaria-associated morbidity and the cost of treatment are important burdens, and create barriers for the overall social and economic development.

There is a high incidence of malaria in the northeastern states of India, which account for $>20 \%$ of the deaths that are reported in the country annually [7-10]. People live under low socio-economic conditions and have high levels of immunity enabling them to serve as reservoirs for malaria transmission [11]. Poor socio-economic conditions, knowledge and perception about malaria and antimalarial policies have contributed to widespread malaria throughout the region $[8,9,12-14]$. Similar to other malaria endemic countries, personal protection using ITNs and malaria treatment with an effective antimalarial are the main strategies against malaria in India (http://www.nvbdcp.gov.in/). The characteristics of the rural environment may also make malaria control difficult due to a high ethnic population density, the geopolitical context and an unfocused nature of malaria vectors breeding sites, which all present major challenges to the integrated malaria control strategies $[7,8,15]$. Various socio-demographic factors, such as ethnic groups, parents' education levels and occupation, use of personal protective measures and family living standards are important risk factors for malaria transmission and epidemics [16].

Knowledge of malaria and socio-economic upliftment are key factors in adopting the appropriate intervention strategies. Keeping in mind that there is a large number of risk factors that influence vulnerability to malaria including proper knowledge about malaria transmission and prevention, demography and socio-economic status of different population groups, the present study was undertaken to identify factors predisposing to malaria in a highly endemic primary health centre in the Udalguri district, Assam, India.

\section{Methods}

\section{Study area}

The Orang primary health centre, situated between $92^{\circ}$ $10^{\prime} 40^{\prime \prime} \mathrm{E}$ longitude to $92^{\circ} 21^{\prime} 20^{\prime \prime} \mathrm{N}$ latitude on the north bank of river Brahmaputra at 105.2 metres above sea level (see Figure 1), is dominated by ethnic tribes of Bodo, Adivasi and Rabha. Low literacy rates, poverty and reluctance to accept medical treatment are common features of these villagers. The climate is humid with semi-dry hot summers and cold winters. The annual rainfall, temperature and humidity of the area ranges from 1500 to $2000 \mathrm{~mm}, 13.5-34.5^{\circ} \mathrm{C}$ and $82-88 \%$, respectively. Malaria is endemic in the entire Orang primary health centre and the majority of the cases fall into the category of Plasmodium falciparum malaria. Malaria transmission is perennial and uninterruptedly supported by malaria vectors, Anopheles dirus, An. minimus, An. fluviatilis, An. annularis and An. culicifacies [11,12,14]. The study area is covered with tea gardens, includes the Rajiv Gandhi Orang National Park and has many small rivers and streams. The primary health centre studied consists of 42 health sub-centres covering a population of around 250,000 people. From a climatic point of view, the study region is conducive to malaria epidemics.

\section{Study design}

A cross-sectional study was carried out from March to September 2012 in four randomly selected health subcentres, namely Kadabil, Dhalanibasti, Gelabil and Bhogdol in the Orang primary health centre, while assuming that all the health sub-centres are homogenous and have a similar malaria situation. During the surveys, about 900 houses were visited to ascertain their willingness to participate in the study, and thereafter a total of 71 household heads representing 385 individual household members were interviewed. In the remaining houses, people were not willing to participate in the study due to one or more of the following reasons: religious beliefs, absence of house head or a feeling that it is not worth participating. Each house represented a family and a household represented the total family members, whereas the head of a household was the person who was perceived to be the primary decision maker in the family. Although the sample size in the present study is small, it is still very useful to take it into consideration when undertaking malaria control efforts in a comparatively inaccessible malaria endemic study area.

\section{Data collection}

Details about personal attributes, knowledge of malaria and socio-economic parameters were recorded in a structured questionnaire that was printed in English and Assamese (local language). A local health worker, in the presence of the community head, recorded the responses 


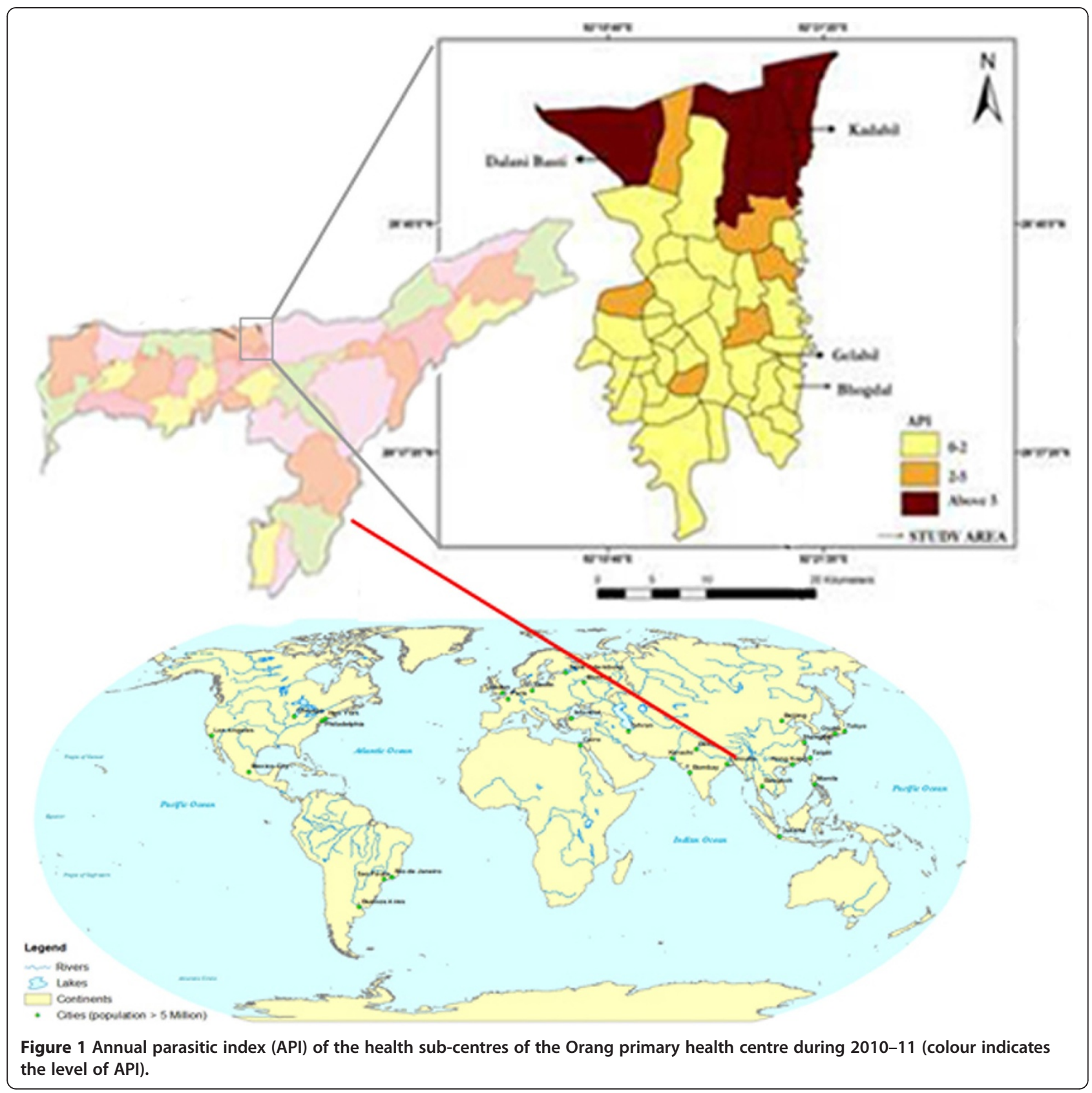

of each individual interviewed by the investigators. The community head and the local health worker are the most respected and trustworthy persons in the community and were therefore involved in the study. Specific variables recorded included: age, gender, education level, knowledge about malaria transmission and prevention, house type, monthly income, other diseases besides malaria, mosquito net use, whether the mosquito net used is the long-lasting insecticidal nets (LLIN)/ITN, frequency of bed net use and source of obtaining bed net, proximity to a health centre and approximate number of mosquito bites per day. The responses of the participants were later verified by their records held at the health sub-centres. Malaria knowledge was ascertained by asking the following questions:

1. What is malaria?

2. How is malaria caused?

3. How does malaria spread?

4. How can malaria be avoided?

5. What is the treatment for malaria?

6. What is the government doing about malaria?

7. Do you know that the government provides bed nets free of charge and antimalarial treatment is available 
free of charge as well in the government health centres?

All seven questions included in the present study were carefully selected and are directly related to malaria aetiology, transmission and prevention. The participants who responded well to all questions were defined as having a good knowledge, those who responded to at least five questions were defined as having an adequate knowledge, while those who could not answer more than three questions were considered to have a poor knowledge. The participants who have monthly incomes of $<2000$ INR (32.14 \$) were recorded as poor, those having 2000-5000 INR (32.14-80.36 \$) were recorded as average, while those having a monthly income of $>5000$ INR (80.36 \$) were recorded as the high-income group. Monthly incomes of the participants were ascertained after asking them about their assets, agriculture produce and other income. In addition to recording the data, in-depth verbal interviews and group discussions were conducted with the local people aggregated during the study, in order to further extrapolate on the findings recorded on the questionnaire sheets. The present study was a part of a larger study being conducted in the region to assess antimalarial resistance and humanhost immune response. The study project was sanctioned by the Department of Defence Research and Development, Government of India and approved by the Institutional Ethical Committee (IEC). Written consent was obtained from the study participants before interviews and all data collected was kept confidential.

\section{Statistical analysis}

Association of malaria occurrence with gender, poverty, house type, knowledge, education, proximity to a health centre, use of bed nets, mosquito bites per day and other awareness parameters were analysed using the chi-square test. Similarly, the trend of malaria occurrence for different income groups, proximity to a health centre and mosquito bites per day was also determined using the chi-square test. Relative risk (RR) for gender, house type, knowledge and use of bed nets was determined using Katz approximation. Odds ratios (OR) for the type of bed net used, knowledge about LLINs and supply of bed nets were determined using Wolf approximation.

\section{Results}

The malaria situation and socio-demographic characterisation

The spatial distribution of malaria prevalence data of all 42 health sub-centres of the Orang primary health centre collected from the state health authority indicated that the API ranged from 0-5 during 2012. Four health sub-centres (9.5\%) had an API of $>5$, while in six (14.3\%) the API ranged from 2 to 5 (see Figure 1). Out of the total 71 household heads interviewed, $70.4 \%$ were males and $29.6 \%$ were females. The average age of the participants was $36.1 \pm 1.7$ (mean \pm SEM) (range $=20-65$; 95\% $\mathrm{CI}=33.1-39.1$, whereas the median number of members per household was five (range $=2-12$ ) (mean \pm $\mathrm{SEM}=5.4 \pm 0.3 ; 95 \% \mathrm{CI}=4.9-5.9$ ) (see Table 1 ). Of the total participants, $54.9 \%(39 / 71)$ had a history of malaria

Table 1 Demographic characteristics and their association with malaria history among the study population in the Orang primary health centre

\begin{tabular}{|c|c|c|c|c|c|}
\hline \multicolumn{2}{|c|}{ Characteristic } & \multirow{2}{*}{$\begin{array}{c}\boldsymbol{N}(\%) \\
33(46.5)\end{array}$} & \multirow{2}{*}{$\frac{p\left(\chi^{2}\right)^{*}}{<0.0001(18.5)}$} & \multirow{2}{*}{$\begin{array}{c}M(\%) \\
25(75.8)\end{array}$} & \multirow{2}{*}{$\frac{p\left(X^{2}\right)^{\#}}{0.004(11.7}$} \\
\hline Age & $15-35$ & & & & \\
\hline & $36-55$ & 28 (39.4) & & 11 (39.3) & \\
\hline & 56 \& above & $10(14.1)$ & & $3(30.0)$ & \\
\hline \multirow[t]{2}{*}{ Sex } & Male & $50(70.4)$ & $<0.0001(23.7)$ & $25(50.0)$ & $0.3(1.1)$ \\
\hline & Female & 21 (29.6) & & $14(66.7)$ & \\
\hline \multirow[t]{2}{*}{ Body Complexion } & Dark & $29(40.8)$ & $0.02(4.1)$ & $22(75.9)$ & $0.007(7.3)$ \\
\hline & Fair & $42(59.2)$ & & $17(40.5)$ & \\
\hline \multirow[t]{2}{*}{ Body Odour } & Strong & $44(62.0)$ & $0.04(7.2)$ & 27 (61.4) & $0.25(1.3)$ \\
\hline & Mild & 27 (38.0) & & $12(44.4)$ & \\
\hline \multirow[t]{2}{*}{ Body Clothing } & $>50 \%$ & $64(90.1)$ & $<0.0001$ (88.3) & $34(54.7)$ & $0.6(0.3)$ \\
\hline & $<50 \%$ & $7(9.9)$ & & $5(71.4)$ & \\
\hline \multirow[t]{2}{*}{ Marital Status } & Married & $63(88.7)$ & $<0.0001(82.3)$ & $33(52.4)$ & $0.4(0.7)$ \\
\hline & UM & $8(11.3)$ & & $6(75.0)$ & \\
\hline \multirow[t]{3}{*}{ Family Size } & $1-3$ & $16(22.5)$ & $<0.0001$ (19.6) & $9(56.3)$ & $0.6(1.0)$ \\
\hline & $4-6$ & $38(53.5)$ & & 19 (50.0) & \\
\hline & $7 \&$ above & $17(23.9)$ & & $11(64.8)$ & \\
\hline
\end{tabular}


in the last two years, of which $64.1 \%(25 / 39)$ were males and $35.9 \%(14 / 39)$ were females $\left(\mathrm{X}^{2}=5.13 ; \mathrm{p}=0.02 ; \mathrm{RR}=\right.$ 1.79; $95 \% \mathrm{CI}=1.10-2.89)$. The education level of $76.1 \%$ (54/71) participants was below primary, and only $9.9 \%$ (7/71) had a good knowledge of malaria. At least $46.5 \%$ $(33 / 71)$ were poor, $49.3 \%(35 / 71)$ lived in bamboo houses and $35.2 \%(25 / 71)$ had their nearest dispensary at a distance of $>3 \mathrm{~km}$ (see Table 2). Most participants (76.1\%) reported having $>$ five mosquito bites every day, $70.4 \%$ (50/71) reported daily bed net use and $50.7 \%(36 / 71)$ used LLINs. All the LLINs were provided by the Assam State Government agency, while only $15.5 \%$ of the participants were aware about the LLINs (see Table 3).

\section{Risk factor analysis for malaria occurrence}

In the univariate analysis, significant associations were observed between malaria infection and selected sociodemographic characteristics of the study participants. The occurrence of malaria was found to be statically similar among both sexes $\left(x^{2}=1.1 ; p=0.3\right)$. Significantly more malaria cases were observed among poor people (71.8\%) who had a monthly income of $<2000$ INR as compared to those who had a monthly income of $>2000$ INR $\left(\chi^{2}=24.2 ; \mathrm{p}<0.0001\right)$. Malaria cases decreased with an increasing monthly income $(\mathrm{p}<0.0001)$. House type was significantly associated with malaria occurrence $\left(x^{2}=17.0 ; p=0.0002\right)$. Malaria was reported to be prevalent among $69.2 \%$ (27/39) of the households living in bamboo houses, as compared to $20.5 \%$ living in Kucha houses $(8 / 39)$ and $10.3 \%$ in Pucca houses (4/39). Knowledge and awareness of malaria significantly influenced the malaria

Table 2 Socio-economic characteristics of the study population in the Orang primary health centre

\begin{tabular}{|c|c|c|c|}
\hline Characteristics & & $N(\%)$ & $p\left(x^{2}\right)$ \\
\hline \multirow[t]{2}{*}{ Education } & Primary & $54(76.1)$ & $<0.0001(36.5)$ \\
\hline & Above Primary & $17(23.9)$ & \\
\hline \multirow{3}{*}{$\begin{array}{l}\text { Monthly Income } \\
\text { in Indian Rupee }\end{array}$} & $<2000$ (32.14\$) & $33(46.5)$ & $<0.0001$ (33.1) \\
\hline & $\begin{array}{l}2000-5000 \\
(32.14-80.36 \$)\end{array}$ & $33(46.5)$ & \\
\hline & $>5000$ (80.36\$) & $5(7.0)$ & \\
\hline \multirow[t]{3}{*}{ House Type } & Bamboo & $35(49.3)$ & $<0.0001(30.5)$ \\
\hline & Kucha & $30(42.3)$ & \\
\hline & Pucca & $6(8.5)$ & \\
\hline \multirow[t]{3}{*}{ Information Source } & Newspaper & $3(4.2)$ & $<0.0001(50.9)$ \\
\hline & TV/Radio & $43(60.6)$ & \\
\hline & None & $25(35.2)$ & \\
\hline \multirow{3}{*}{$\begin{array}{l}\text { Distance to Nearest } \\
\text { Health Centre }\end{array}$} & $<1 \mathrm{Km}$ & $31(43.7)$ & $0.02(8.3)$ \\
\hline & $1-3 \mathrm{Km}$ & $15(21.1)$ & \\
\hline & $>3 \mathrm{Km}$ & $25(35.2)$ & \\
\hline
\end{tabular}

$\mathrm{N}$ - total number of participants.
Table 3 Malaria epidemiology related characteristics of the study population in the Orang primary health centre

\begin{tabular}{llll}
\hline Characteristics & & $\boldsymbol{N}(\%)$ & $\boldsymbol{p}\left(\mathbf{x}^{2}\right)$ \\
\hline Knowledge About Malaria & Poor & $31(43.7)$ & $<0.0001(26.5)$ \\
& Adequate & $33(46.5)$ & \\
& Good & $7(9.9)$ & \\
Water Source Near House & River & $8(11.3)$ & $<0.0001(112.4)$ \\
& Nallah & $5(7.0)$ & \\
& Well/Tank & $58(81.7)$ & \\
Bed Net Use & Daily & $50(70.4)$ & $<0.0001(79.9)$ \\
& Mostly & $21(29.6)$ & \\
Bed Net Type & Never & $0(0.0)$ & \\
& LLIN & $36(50.7)$ & $0.87(0.03)$ \\
Source of Bed Net & ITN & $35(49.3)$ & \\
& Govt. & $36(50.7)$ & $0.87(0.03)$ \\
& Own & $35(49.3)$ & \\
\hline
\end{tabular}

$\mathrm{N}$ - total number of participants.

occurrence among the participants. Malaria was prevalent among $69.2 \%(27 / 39)$ of the participants who had a poor knowledge about malaria $\left(\chi^{2}=25.5 ; \mathrm{p}<0.0001\right)$. Distance to the nearest dispensary was significantly associated with malaria occurrence as well. Malaria was observed to be higher among those who needed to travel more to assess the nearest health facility $\left(\chi^{2}=25.0 ; \mathrm{p}<0.0001\right)$. There was a significant linear trend between malaria occurrence and distance to a health facility as more cases were observed among the households who had the nearest health facility at a distance of $>3 \mathrm{~km}\left(\mathrm{x}^{2}=24.7 ; \mathrm{p}<0.0001\right)$.

Although $76.1 \%(54 / 71)$ of the participants who had malaria also had a below primary education level, there was no significant association between the education level of the participants and the occurrence of malaria $\left(\chi^{2}=0.008 ; \mathrm{p}<0.93 ; \mathrm{RR}=0.91 ; 95 \% \mathrm{CI}=0.57-1.46\right)$. The number of mosquito bites was significantly associated with malaria occurrence among the participants. Malaria occurrence was observed among all the participants who reported to receive $>10$ mosquito bites, as compared to those who received $<10$ mosquito bites per day. The difference was statically significant $\left(\chi^{2}=10.1 ; \mathrm{p}<0.006\right)$, and a significant linear trend was observed between malaria occurrence and the number of mosquito bites per day $\left(x^{2}=9.7 ; p<0.001\right)$. Use of bed net was associated with malaria as the number of participants who did not use bed nets regularly reported a high occurrence of malaria infection as compared to those who used bed nets daily $\left(\mathrm{X}^{2}=17.33 ; \mathrm{p}<0.0001\right)$. There was a significant association observed between the supply and type of bed nets used and the occurrence of malaria. Among the participants who reported malaria, 79.5\% (31/39) used LLINs as compared to the ITNs $\left(\chi^{2}=7.6 ; \mathrm{p}<0.003\right.$; $\mathrm{OR}=0.27(95 \% \mathrm{CI}=0.11-0.66)$. 


\section{Discussion}

Although substantial progress has been made in controlling malaria, approximately 1.3 billion people continue to be at risk in the Southeast Asian region. Ten of the eleven member nations of the WHO-SEA region are malaria endemic, contributing $15 \%$ to the global malaria burden [17]. In addition to killing thousands of people, malaria is an enervating disease that creates a massive socio-economic burden globally, mainly for poor people living in areas with limited access to health care [18]. The Udalguri district is a malaria prone area, reporting API of $>10$ in the majority of the health sub-centres in recent years [9]. An estimated $54 \%$ of the population of the Udalguri district lives below the poverty line and is dominated by tribal communities. The tribal people benefit the least from the socio-economic development and still prefer to use traditional systems to treat diseases [19].

The results of malaria occurrence among both sexes were similar to the previous studies conducted in the region $[7,8,20]$. However, some studies have suggested that females are more vulnerable to malaria as they are in charge of many household activities, which cause them to be at a greater risk of acquiring the malaria infection [21]. Poverty was associated with malaria occurrence in the study population. Many studies have regarded malaria as a disease of the poor, which is substantiated by the fact that the malaria burden is often concentrated in the poorest continents and countries [21-25]. The poor have comparatively less access to antimalarials and antimosquito measures, since they cannot afford personal protection measures, a clean environment free of mosquito breeding sites, and are particularly vulnerable to the impact of ineffective diagnosis and treatment due to financial and cultural implications. Further, the poor population is often heavily marginalised by the health sector and survives under tremendous burden of malaria and other communicable diseases [26]. Bamboo houses and a greater number of mosquito bites per day were positively associated with a history of malaria. It is most likely that poorly constructed bamboo houses might have a number of gaps and holes through which a vector mosquito could easily enter following the scent of human hosts. A recent study in Laos suggested that good quality houses could reduce disease transmission by reducing the human-mosquito contact [27].

There was a strong association between common knowledge and awareness about malaria and occurrence of malaria among the study participants. The participants who satisfactorily responded to the questions about malaria transmission and prevention were less affected by malaria as compared to those who had a poor knowledge. On the other hand, the level of education of the participants did not have any impact on the occurrence of malaria. A previous study conducted in Lagos also indicated that education was not significantly associated with malaria infection among pregnant women [28]. Community knowledge and awareness has a significant influence on malaria control, and individual knowledge, awareness and beliefs may also affect malaria occurrence. The misconception and beliefs about malaria among some communities continuously battle with the correct scientific information and pose major setbacks in malaria control efforts $[3,29,30]$.

Distance from the house to the nearest health facility was another risk factor for malaria occurrence. Many previous similar studies have reported that distance to health centres influenced the treatment seeking behaviour of individuals, compounding the malaria situation [31]. The distance to a health centre could be regarded as a factor for health facility accessibility for which the cost of reaching a health centre is met by the patients. A problematic distance to a health centre may result in a household not assessing the health facility frequently due to the cost and loss of work time. Our findings suggest that household members whose houses are close to health centres have more and more timely access to health care as compared to those whose houses are far away from health centres. Further, the households who live closer to health centres have more knowledge and awareness as they have more interaction with the health staff.

We found that the number of mosquito bites received by participants influenced malaria occurrence. The higher the number of mosquito bites per day, the greater the risk of malaria infection [32]. Use of the bed nets was found to be associated with malaria occurrence as well. The households who used bed nets frequently, but not daily were more affected by malaria as compared to those who used bed nets every night. Although, the bed nets were available in every house in the study area, the number was probably still insufficient to achieve total coverage. Therefore, each household did not use bed nets regularly. Further, malaria occurrence was found to be higher among those who used LLINs as compared to those who used ITNs. Many studies have concluded that ITN coverage was related to malaria control knowledge, significantly reduced malaria and was associated with a malaria riskprotective effect [31,33-37]. Although LLINs have been recommended widely as they remain effective for several years, ITNs have also proved to be effective in reducing all causes of malaria mortality and morbidity [33,37]. Insecticide-treated bed nets (ITNs) are easy to use and require less capital outlay as compared to the LLINs, and this might lead to a widespread use of ITNs on a large scale. Studies have indicated that LLINs get damaged at a faster rate in operational conditions and holes and other entry places for mosquitoes are more easily formed. Moreover, torn and improperly used LLINs allow vector mosquitoes to enter and bite the user [38]. 
Insecticide-treated bed nets (ITNs) have also been shown to provide substantial protection against malaria, however the sustainable use of ITNs needs regular insecticide retreatment as they lose efficacy after some time [39].

Although malaria distribution is mostly determined by the climatic and environmental factors which affect mosquito and malaria parasite reproduction and proliferation at a given time, malaria is also influenced by various socio-economic factors $[3,4,26,28,40,41]$. In the current study, important associations between malaria occurrence and risk factors were observed which cannot be explained by any of the factors included in this analysis. Although many factors were associated with malaria occurrence, none of the factors could singly be targeted for comprehensive malaria control. Malaria occurrence is a complex interplay of various factors, which may be region specific and most of which are inter-dependent upon each other. A better understanding of the association between malaria and associated factors is required to design effective policies to tackle malaria. The present study is first of its kind and documents that there are certain key factors which need to be taken into consideration when allocating funds for addressing the malaria problem in the region.

Although the study offers some important findings, it has also some limitations. The study is cross sectional and the sample size is not very large, therefore the possibility of sampling error cannot be overruled. Malaria occurrence was based on the history but not actual testing. Further, the perception of risk and actual malaria incidence vary geographically and seasonally. The study did not involve questions on the re-treatment and age of ITNs. Also, the study used ITNs and LLINs as the sole indicator of control measures, but the usage of IRS, mosquito repellent coils and creams was not assessed.

\section{Conclusion}

In the study area, malaria occurrence was higher among participants who had lower incomes, lived in bamboo houses and were located at a considerable distance from a health sub-centre. Further, knowledge and awareness about malaria, number of mosquito bites per day and use of bed nets were also associated with malaria occurrence. However, the education level of the study participants had no role in malaria occurrence. Although malaria incidence depends on various variables, the present study demonstrates that those variables related to poverty, poor health infrastructure and awareness about malaria are the most important factors in minimising the risk of malaria.

\section{Additional files}

Additional file 1: Multilingual abstracts in the six official working

languages of the United Nations.

\section{Competing interest}

The authors declare that they have no competing interest.

\section{Authors' contributions}

KY, PKS and SD conceived the idea. SD, KY and BR collected the data. SD and $K Y$ analysed the data. KY prepared the map. SD, BR and KY drafted the manuscript. PKS and $W$ edited the manuscript and extended technical support. All authors read the manuscript and approved the draft.

\section{Acknowledgements}

The authors wish to thank Dr Davidson $\mathrm{H}$ Hamer, Professor of International Medicine and Health, Boston University School of Medicine, for his critical review and comments on the manuscript.

\section{Author details}

${ }^{1}$ Defence Research Laboratory, Tezpur, Assam 784001, India. ${ }^{2}$ Department of Zoology, Gauhati University, Guwahati, India.

Received: 27 November 2013 Accepted: 17 June 2014

Published: 24 June 2014

\section{References}

1. World Health Organization: World malaria report. 2013. Available on http:// www.who.int/malaria/media/world_malaria_report_2013/en/index.html) (Cited on 09 Jan 2014.

2. Gwatkin D, Guillot M: The burden of disease among the global poor: current situations, future trends, and implications for strategy. Washington DC, USA: World Bank; 2000.

3. Dhiman SK: Malaria control: Behavioural and social aspects. DRDO Sci Spec 2009, 183-186.

4. Gallup JL, Sachs JD: The economic burden of malaria. Am J Trop Med Hyg 2001, 64(1,2):85-96.

5. Heggenhougen HK, Hackethal V, Vivek P: The behavioural and social aspects of malaria and its control. In UNDPMorld BankWHO, Special Programme for Research and Training in Tropical Diseases (TDR), TDR/STR/SEB/ VOL/03.1. Geneva: World Health Organization; 2003.

6. Enayati A, Hemingway J: Malaria management: Past, present and future. Annu Rev Entomol 2010, 55:569-591.

7. Dhiman S, Gopalakrishnan R, Goswami D, Baruah I, Singh L: Malaria epidemiology along Indo-Bangladesh border in Tripura state, India. Southeast Asian J Trop Med Pub Health 2010, 41(6):1279-1289.

8. Rabha B, Goswami D, Dhiman S, Das NG, Talukdar PK, Nath MJ, Baruah I, Bhola RK, Singh L: A cross sectional investigation of malaria epidemiology among seven tea estates in Assam, India. J Parasit Dis 2011, 36:1-6.

9. Yadav K, Nath MJ, Talukdar PK, Saikia PK, Baruah I, Singh L: Malaria risk areas of Udalguri district of Assam, India: a GIS-based study. Int J Geogr Inf Sci 2012, 26(1):123-131.

10. Nath MJ, Bora AK, Yadav K, Talukdar PK, Dhiman S, Baruah I, Singh L: Prioritizing areas for malaria control using geographical information system in an endemic district of Assam, India. Public Health 2013, 127:572-580.

11. Dev V, Bhattacharyya PC, Talukdar R: Transmission of malaria and its control in northeastern region of India. J Assoc Physicians India 2003, 51:1073-1076.

12. Dev V, Phookan S, Sharma VP, Anand SP: Physiographic and entomologic risk factors of malaria in Assam, India. Am J Trop Med Hyg 2004, 71:451-456.

13. Dev V, Phookan S, Sharma VP, Dash AP, Anand SP: Malaria parasite burden and treatment seeking behavior in ethnic communities of Assam, Northeastern India. J Infect 2006, 52:131-139.

14. Das NG, Talukdar PK, Kalita J, Baruah I, Sribastava RB: Malaria situation in forest-fringed villages of Sonitpur district (Assam), India bordering Arunachal Pradesh during an outbreak. J Vector Borne Dis 2007, 44(3):213-218.

15. Sharma VP: Battling malaria iceberg incorporating strategic reforms in achieving millennium development goals \& malaria elimination in India. Indian J Med Res 2012, 136(6):907-925.

16. Kreuels B, Kobbe R, Adijei S, Kreuzberg C, Von Reden C, Bater K, Klug S, Busch W, Adijei O, May J: Spatial variation of malaria incidences in young children from a geographically homogeneous area with high endemicity. J Infect Dis 2008, 197:85-93. 
17. World Health Organization: WHO calls for greater investment to eliminate malaria. In WHO, SEAR/PR 1557. ; 2013. (Available at http://www.searo.who. int/ mediacentre/releases/2013/pr1557/en/) (Cited on 25 July 2013].

18. Sachs J, Malaney P: The economic and social burden of malaria. Nature 2002, 415:680-685.

19. Chaturvedi HK, Mahanta J, Pandey A: Treatment-seeking for febrile illness in north-east India: an epidemiological study in the malaria endemic zone. Malar J 2009, 8:301.

20. National Vector Borne Disease Control Programme: State programme implementation plan 2011-12. India: NVBDCP, NRHM Assam; 2010. 355-488.

21. Ayele DG, Zewotir TT, Mwamb HG: Prevalence and risk factors of malaria in Ethiopia. Malar J 2012, 11:195.

22. World Health Organisation: Department of Gender, Women and Health (GWH). Gender, Health and Malaria, WHO Fact sheet. Geneva: WHO, press; 2007. Available on http://www.who.int/gender/documents/ gender_health_malaria.pdf) (Cited on 27 Jul 2013.

23. Sharma VP: Malaria and poverty in India. Curr Sci 2003, 84(4):513-515.

24. Worrall E, Basu S, Hanson K: Is malaria a disease of poverty? A review of the literature. Trop Med Int Health 2005, 10(10):1047-1059.

25. Amegah AK, Damptey OK, Sarpong GA, Duah E, Vervoorn DJ, Jaakkola JJK: Malaria infection, poor nutrition and indoor air pollution mediate socioeconomic differences in adverse pregnancy outcomes in Cape Coast, Ghana. PLoS One 2013, 8(7):e69181.

26. Ajayi IO, Jegede AS, Falade CO, Sommerfeld J: Assessing resources for implementing a community directed intervention (CDI) strategy in delivering multiple health interventions in urban poor communities in Southwestern Nigeria: a qualitative study. Infect Dis Poverty 2013, 2:25.

27. Hiscox A, Khammanithong P, Kaul S, Sananikhom P, Luthi R, Hill N, Brey PT, Lindsay SW: Risk factors for mosquito house entry in the Lao PDR. PLoS One 2013, 8(5):e62769.

28. Agomo CO, Oyibo WA: Factors associated with risk of malaria infection among pregnant women in Lagos Nigeria. Infect Dis Poverty 2013, 2:19.

29. Wakgari D, Ahmed A, Damen H: Malaria related health seeking behaviour and challenges for care providers in rural Ethiopia implications for control. J Biosoc Sci 2008, 40:1-21.

30. Alemu A, Tsegaye W, Golassa L, Abebe G: Urban malaria and associated risk factors in Jimma town, south-west Ethiopia. Malar J 2011, 10:173.

31. Lowassa A, Mazigo HD, Mahande AM, Mwang'onde BJ, Msangi S, Mahande MJ Kimaro EE, Kweka Elisante E, Kweka EJ: Social economic factors and malaria transmission in Lower Moshi, Northern Tanzania. Parasit Vectors 2012, 5:129.

32. Smith DL, McKenzie FE, Snow RW, Hay SI: Revisiting the basic reproductive number for malaria and its implications for malaria control. PLOS Biol 2007, 5(3)::42

33. Mulligan JA, Yukich J, Hanson K: Costs and effects of the Tanzanian national voucher scheme for insecticide-treated nets. Malar J 2008, 7:32.

34. Prakash A, Bhattacharyya DR, Mohapatra PK, Goswami BK, Mahanta J: Community practices of using bed nets \& acceptance \& prospects of scaling up insecticide treated nets in north-east India. Indian $J$ Med Res 2008, 128:623-629.

35. Ahmed SM, Hossain S, Kabir MM, Roy S: Free distribution of insecticidal bed nets improves possession and preferential use by households and is equitable: findings from two cross-sectional surveys in thirteen malaria endemic districts of Bangladesh. Malar J 2011, 10:357.

36. Bhatt RM, Sharma SN, Uragayala S, Dash AP, Kamaraju R: Effectiveness and durability of Interceptor ${ }^{\oplus}$ long-lasting insecticidal nets in a malaria endemic area of central India. Malar J 2012, 11:189.

37. Rulisa S, Kateera F, Bizimana JP, Agaba S, Dukuzumuremyi J, Baas L, Harelimana JD, Mens PF, Boer KR, Vries PJ: Malaria prevalence, spatial clustering and risk factors in a low endemic area of Eastern Rwanda: A cross sectional study. PLoS One 2013, 8(7):e69443.

38. Gnanguenon V, Azondekon R, Oke-Agbo F, Sovi A, Osse R, Padonou G, Aikpon R, Akogbeto MC: Evidence of man-vector contact in torn long-lasting insecticide-treated nets. BMC Public Health 2013, 13:751.

39. Hanson K, Marchant T, Nathan R, Mponda H, Jones C, Bruce J, Mshinda H, Schellenberg JA: Household ownership and use of insecticide treated nets among target groups after implementation of a national voucher programme in the United Republic of Tanzania: plausibility study using three annual cross sectional household surveys. BMJ 2009, 339:b2434.
40. Nath MJ, Bora A, Talukdar PK, Das NG, Dhiman S, Baruah I, Singh L: A longitudinal study of malaria associated with deforestation in Sonitpur district of Assam India. Geocarto Int 2012, 27(1):79-88

41. West PA, Protopopoff N, Rowland M, Cumming E, Rand A, Drakeley C, Wright A, Kivaju Z, Kirby MJ, Mosha FW, Kisinza W, Kleinschmidt I: Malaria risk factors in North West Tanzania: The effect of spraying, nets and wealth. PLoS One 2013, 8(6):e65787.

doi:10.1186/2049-9957-3-19

Cite this article as: Yadav et al: Socio-economic determinants for malaria transmission risk in an endemic primary health centre in Assam, India. Infectious Diseases of Poverty 2014 3:19.

\section{Submit your next manuscript to BioMed Central and take full advantage of:}

- Convenient online submission

- Thorough peer review

- No space constraints or color figure charges

- Immediate publication on acceptance

- Inclusion in PubMed, CAS, Scopus and Google Scholar

- Research which is freely available for redistribution

Submit your manuscript at www.biomedcentral.com/submit
() Biomed Central 